\title{
A atuação do Ministério Público nas investigações criminais à luz dos princípios constitucionais relacionados
}

\author{
Bruna Azevedo de Castro ${ }^{1}$
}

\section{Resumo}

Discutir a possibilidade de intervenção do Ministério Público nas investigações criminais sob um prisma constitucional e, ainda, relacionar tal possibilidade com função desempenhada pela polícia judiciária. Destacar os posicionamentos doutrinários divergentes quanto à interpretação dos dispositivos constitucionais. Enfocar os princípios constitucionais e constitucionais penais concernentes à investigação criminal presidida pelo Ministério Público.

Palavras Chave: Ministério Público; Investigação Criminal; Constituição Federal.

\section{Introdução}

As veredas trilhadas pela transformação social do Brasil, desde a promulgação da Constituição de 1988, têm exteriorizado nada além as conseqüências da evolução do processo democrático no País.

O Estado Democrático de Direito, forçado a um amadurecimento precoce, não se subjuga ao enfraquecimento, ainda que diante de crises sucessivas de suas instituições.

O Ministério Público, como assaz sabido, exerce funções essenciais à justiça, tal como dispõe e, em seguida, arrola a Constituição Federal, em seu Art. 129 e incisos. A promulgação da lex mater é considerada o auge da importância conferida a essa esplêndida instituição, na medida em que Ihe garante autonomia, independência funcional, direitos e deveres paritários aos da magistratura.

O tema do presente trabalho não pode ser dissociado da verificação dos novos rumos do Estado Democrático de Direito que reflete diretamente nos contornos do Direito e Processo Penal.

\footnotetext{
Aluna do Curso de Especialização em Direito e Processo Penal da Universidade Estadual de Londrina.
} 
A função investigatória do Ministério Público no âmbito criminal deve ser analisada sob uma perspectiva dotada de integral acuidade, em atenção aos princípios constitucionais informadores do processo penal pois, o que mitiga um princípio constitucional agride diretamente a Constituição.

\section{Enfoque constitucionalista do direito penal}

A crise por que passa o direito penal, dezessete anos após a promulgação da Constituição, não tem outra coisa senão uma estreita correlação com a intricada fase por que também passa a concepção de bem jurídico no atual Estado Constitucional Democrático de Direito. Como bem se esclarece, insta que a hierarquia dos bens jurídicos sofra um redimensionamento estrutural, aclimando-os na dignidade da ordem constitucional (STRECK; FELDENS, 2003, p. 23).

Consoante ensinamento de Streck (2004, p. 78), o Direito representado pelo modelo brasileiro afasta-se relevantemente do objetivo de solver as necessidades oriundas de uma sociedade complexa, calcada por insípidas desigualdades. Percebe-se uma inversão nefasta de valores dos bens jurídicos, de modo que se faz preponderar quaisquer vias de solução de conflitos individuais. Sumulando dos reflexos da crise jurídica instaurada, é pertinente assentar o juízo de que o valor da Constituição e do Constitucionalismo não é ou não está sendo distinguido pela comunidade jurídica da maneira como deveria ser.

Luiz Regis Prado (2003, p.104-105) com a acuidade que lhe é intrínseca, assevera restar evidente que a noção de bem jurídico advém das necessidades do homem originadas na experiência da vida concreta. As necessidades individuais convertem-se em valores culturais quando socialmente dominantes; valores tais que se transfiguram em bens jurídicos quando constatada a necessidade de proteção jurídica dos mesmos em razão da sobrevivência do homem e sua harmoniosa convivência social.

Luiz Flávio Gomes e Alice Bianchini (2002, p. 58) argumentam que a pretensão estatal de disciplinar e regular tudo, recorrendo quase sempre ao instrumento penal é a primordial causa da maior crise do direito penal na era da globalização, crise esta a que se confere a denominação "hipertrofia do Direito Penal".

Opera-se, pois, severa crítica à criminalização exacerbada de condutas atentatórias contra determinados bens jurídicos de feição supraindividual justamente porque, parte 
desses comportamentos poderia sofrer reprimenda meramente administrativa, ao invés de acionar a jurisdição criminal, que já se encontra demasiadamente hipertrofiada.

O debate fomentado por esta nova ordem de valoração do bem jurídico especialmente o penal - percute, por óbvio, na margem de atuação do Ministério Público enquanto um dos arautos na defesa dos direitos fundamentais.

A Constituição Federal de 1988 consolidou a o Ministério Público, definitivamente, enquanto Instituição atuante e indispensável; desde então, o que se tem verificado não poder ser outro panorama senão a realização, pelos membros do Parquet, de todas as prerrogativas constitucionalmente auferidas.

\section{Funções institucionais penais do Ministério Público}

\subsection{A titularidade privativa da ação penal}

A Constituição Federal atribuiu ao Ministério Público, com exclusividade, a titularidade para propor a ação penal pública, tanto a incondicionada como a condicionada, sujeita à representação (Art. 129, I). Quanto à ação penal pública, também interessa mencionar o Art. 5으, LIX que permite ação penal privada nos crimes de ação pública, se esta não for intentada no prazo legal.

A propositura da ação penal, diante de um fato típico, ilícito e culpável, não se trata de uma mera faculdade, mas um verdadeiro poder-dever estatal, cujo exercício é atribuído ao Ministério Público, para restauração da ordem jurídica violada.

A ação penal, pública ou privada, não resguarda o escopo de esgotar o espaço físico e burocrático do sistema carcerário brasileiro, e sim, por meio da instrução contraditória e busca da verdade real, restaurar a ordem jurídica violada de forma justa e segura. Isto é assim porque ao Estado não interessa a absolvição de um culpado, também não Ihe interessa a condenação de um inocente (JARDIM, 1998, p. 17).

Como titular da ação penal pública, deve o membro do Parquet zelar por uma correta e justa instrução criminal, resguardando às partes todos os direitos e garantias constitucionais inerentes tanto ao direito processual como ao direito material, para não se afastar, em nenhum momento, do genuíno propósito da ação, que é a solução justa do conflito, implicando isto ou não a condenação do denunciado. 


\subsection{Requisição de diligências investigatórias e instauração de inquérito policial}

O Ministério Público é autorizado constitucionalmente (Art. 129, VIII, primeira parte) a requisitar diligências investigatórias que entender imprescindíveis em quaisquer das fases da persecução penal: a investigação criminal e a ação penal propriamente instaurada.

Assim expressa o Art. 16 do Código de Processo Penal: “O Ministério Público não poderá requerer a devolução do inquérito à autoridade policial, senão para novas diligências, imprescindíveis ao oferecimento da denúncia".

Conclui-se, pois, que não é permitido ao Ministério Público simplesmente ignorar os autos de inquérito policial, a devolução à Autoridade Policial deve ser fundamentada. Ademais, a Autoridade Policial não é hierarquicamente inferior ao Ministério Público, mas sim colaboradora da Justiça Penal (TOURINHO FILHO, 1997, p. 217).

O raciocínio dos que se colocam favoravelmente às investigações criminais realizadas pelo Ministério Público é embasado na tese de que, podendo o Ministério Público fazer o mais - requisitar que se faça -, não lhe poderia ser vedado fazer o menos - realizálas pessoalmente (RANGEL, 2003, p. 190).

O mesmo inciso VIII do Art. 129 da Carta Política também outorgou ao Ministério Público a prerrogativa de requisitar instauração de Inquérito Policial. O termo "requisitar" não equivale a "solicitar", consubstanciando uma exigência legal ao seu destinatário, ainda que não possua coercibilidade, pois este atributo é próprio das decisões judiciais (STRECK; FELDENS, 2003, p. 84).

Deverá a requisição ministerial sobejar-se de elementos suficientes para constituir o mínimo de lastro probatório coerente com a necessidade de uma investigação. Destarte, quando vagos os dados fornecidos pela requisição ministerial de instauração de inquérito, à Autoridade Policial caberá dirigir ofício ao Ministério Público, evidenciando a impossibilidade de investigação ante a ausência de robustez dos fatos e dados fornecidos e, a um só tempo, solicitar-Ihe informações mais precisas (TOURINHO FILHO, 1997, p. 218).

O membro do Parquet, ao requisitar instauração de Inquérito Policial para formação da opinio delicti, deverá atentar-se, também, à real necessidade de investigação, já que é reprovável a movimentação de um órgão público em vão e, tão mais reprovável seria o 
transtorno causado ao indivíduo que passa pelo indiciamento desnecessário, certamente fadado ao arquivamento ${ }^{2}$.

\subsection{Exercício do controle externo da polícia judiciária}

Cumpre verificar, inicialmente, o que significa controle externo. Manifestam-se Cláudio e Tovo (1999, p. 41) no sentido de moldar um conceito de controle externo como sendo aquele que vem de fora e se exerce, no âmbito do processo penal, sobre a polícia judiciária.

A Constituição Federal, quando prevê a necessidade de controle externo da atividade policial, não tem o escopo de diminuir a sua importância na persecução penal. $A$ finalidade, em verdade, é sempre a mesma: a apuração da prática de uma infração penal, perseguir respaldo e elementos de convicção.

Equivocada é a pretensão de que o controle da atividade policial elaborada pelo Texto de 88 teve por impulso a desconfiança da população em relação ao aparelhamento policial e a concentração de poderes que ele detém em suas mãos (VALLE, 1984, p. 10), isto porque controle e responsabilização são conceitos intrínsecos à própria idéia de República (SANTOS GONÇALVES, 2004, p. 160).

A atuação ministerial de controle externo da polícia judiciária está, assim, condicionada a uma necessidade essencial de proteção a direitos e garantias fundamentais ou de suplementação substancial das informações oferecidas pela investigação.

\section{Princípios constitucionais pertinentes à investigação criminal realizada pelo Ministério Público}

A dissertação sobre qualquer assunto cujo enfoque direcione-se a uma análise de determinados princípios de direito, requer, previamente, uma exposição clara, ainda que concisa, acerca do conceito de princípio.

\footnotetext{
2 A Autoridade Policial não pode arquivar o Inquérito de ofício, deverá requerer ao juiz competente para que seja aberta vista ao promotor. Neste diapasão, o membro do Parquet, entendendo ser o arquivamento a medida mais correta, caber-lhe-á peticionar à autoridade judiciária requerendo, fundamentadamente, o sobrestamento da peça informativa sob comento. (Art. 18 c/c Art 28 do Código de Processo Penal).
} 
Esta seção refere-se, especialmente, aos princípios constitucionais diretamente relacionados à discussão doutrinária e jurisprudencial que toma o centro do presente trabalho.

Os princípios a seguir aventados são classificados por alguns doutrinadores como garantias constitucionais e não princípios, o que não é incoerente, pois se encontram materializados em incisos do Art. 5으 da Constituição Federal, cujo título dispõe justamente quanto aos direitos e garantias fundamentais.

Fundamental é a diferenciação oferecida por José Afonso da Silva (2000, p. 95-96) entre princípios e normas:

\begin{abstract}
As normas são preceitos que tutelam situações subjetivas de vantagem ou de vínculo, ou seja, reconhecem, por um lado, a pessoas ou a entidades a faculdade de realizar certos interesses ou ato próprio ou exigindo ação ou abstenção de outrem, e, por outro lado, vinculam pessoas ou entidades à obrigação de submeter-se às exigências de realizar uma prestação, ação ou abstenção em favor de outrem.Os princípios são ordenações que se irradiam e imantam o sistema de normas [...].
\end{abstract}

Em seguida, salienta o autor que parte dos estudiosos entende que princípio e regra constituem espécies do gênero normas. Esta distinção, contudo, exige uma análise mais percuciente, o que certamente não condiz com a finalidade precípua do trabalho.

Marques de Lima (2002, p. 61) revela uma esclarecedora conceituação, afirmando que os princípios são cláusulas genéricas que enunciam imperativos de justiça ou de alguma outra dimensão de moralidade, refletindo a dimensão jurídica desta.

Na hipótese não rara de princípios de direito entrarem em conflito, o embate não faz com que nenhum deles seja excluído do sistema, ao contrário, a solução pode afastar de maneira provisória a incidência de um deles para que o outro, no caso concreto, possa prevalecer (MARQUES DE LIMA, 2002, p. 61).

As garantias, um conceito mais abstrato, positivam-se por meio de regras ou princípios. Desta feita, é possível que um princípio revele uma garantia, porquanto ambos não traduzam o mesmo conceito. É válido afirmar que garantias assumem a forma ora de princípios, ora de regras, através dos quais se positivam e se expressam. (MARQUES DE LIMA, 2002, p. 61). 
Proceder-se-á nos itens próximos a um estudo dos princípios ou garantias constitucionais concernentes ao direito material e processual penal à luz da discussão central do tema deste trabalho.

Pormenorizar o estudo de princípios constitucionais mediante um conflito judicial ou uma polêmica doutrinária está, indiscutivelmente, dentre as principais e obrigatórias funções do operador do direito.

Lamentavelmente, muitos recursos são levados ao Pretório Excelso argüindo inconstitucionalidade de decisões judiciais que, sustentadas por preceitos infraconstitucionais - não raras vezes incompatíveis com a finalidade constitucional revelam, manifestadamente, desarmonia contundente com princípios constitucionais.

Decisões judiciais, atos administrativos e até mesmo leis infraconstitucionais que se confrontem diretamente com princípios constitucionalmente firmados, acometem-se a uma inconstitucionalidade indecorosa.

\subsection{O devido processo legal}

Com a leitura do Art. 5ㅇ, LIV da Constituição Federal, é possível definir, de forma simplista, o princípio do devido processo legal consistindo em uma garantia de toda pessoa ao direito de não ser privada de sua liberdade ou de seus bens sem que the seja assegurado o devido processo legal.

Scarence Fernandes (2000, p. 45), sobre a generalidade da garantia do devido processo legal, dispõe o seguinte:

\footnotetext{
Consiste na introdução, nas Constituições, além das garantias explícitas, de regra genérica que assegure a todos a garantia do devido processo [...], que, por construções doutrinárias e jurisprudenciais, servirá para que se considere como constitucional determinada garantia não expressa. 0 mesmo sucedeu entre nós com a Constituição de 1988; no art. 5으, inc. LIV, declarou que "ninguém será privado da liberdade ou de seus bens sem o devido processo legal.
}

Verifica-se que o princípio do devido processo legal, por si só, já exaure outras garantias do processo, implícitas em sua interpretação. O processo tem que obedecer $\grave{a}$ prescrição legal e, mais do que isto, tem que atender à Constituição (daí falar-se em devido processo constitucional) (MARQUES DE LIMA, 2002, p. 177). 
Suannes (2004, p. 246) depreende da garantia do devido processo um dos argumentos que contrariam a legitimidade dos procedimentos investigatórios criminais presididos pelo Ministério Público. Segundo o autor, não parece razoável que, havendo um órgão destinado às investigações criminais, a polícia judiciária, o Ministério Público sobreponha-se a ele para exercer a mesma função.

A mitigação do princípio do devido processo legal afigura residir em outro raciocínio. Sob diversos aspectos que serão pormenorizados adiante, a atuação investigatória do Ministério Público na apuração de infrações penais não condiz com a garantia do devido processo legal, uma vez que, no sistema brasileiro, estaria acumulando as funções de investigar e desencadear a ação penal.

Nada obstante a organização policial esteja eivada de irregularidades, advindas do próprio mau aparelhamento e estruturação da mesma, acumular as funções de investigação e promoção da ação penal não impermeabilizaria os membros do Ministério Público do perigo do abuso. Fragoso (2002, p. 244) considera que, além de ilegal e inconstitucional, este acúmulo de atribuições é absolutamente inconveniente, pois dá lugar, pelo excesso de poder, a abusos intoleráveis.

Rangel (2003, p. 65), exprimindo entendimento diverso, assevera que as investigações criminais realizadas diretamente pelo Ministério Público não afetariam sua imparcialidade, um dos pressupostos do devido processo legal. Para tanto, argumenta que $a$ imparcialidade material do membro do Ministério Público não pode ser confundida com a parcialidade instrumental, ou seja, com a capacidade de ser parte, a legitimatio ad causam. Conclui o autor que, tanto o Parquet é imparcial em sua atuação no âmbito do direito material que, caso constate a inocência do denunciado ou ausência de provas para culpabilidade, está autorizado a opinar pela absolvição.

Realmente, a função acusatória que exerce o dominus litis não resguarda característica inquisitorial, pois transpassa os limites da mera persecução de indivíduos a serem condenados.

Entrementes, é a cumulação de funções que traz a lume sério risco de se prostrar os princípios da igualdade do processo, quanto à paridade de armas, o contraditório, especialmente porque o sistema brasileiro não está legitimamente estruturado para um Ministério Público investigador no âmbito criminal. Para isto, seria necessária uma 
normatização pormenorizada das funções investigatórias do Parquet, vale dizer, regulamentações que não passaram pelo processo legislativo adequado à relevância da matéria são, se não inconstitucionais, ao menos ilegítimas.

\subsection{Igualdade processual. Paridade de armas}

O princípio da igualdade processual entre as partes é um desdobramento da garantia constitucional de que todas as pessoas são iguais perante a lei, materializada no Art. 5ำ, caput da Constituição Federal.

Scarance Fernandes (2000, p. 47) desune, didaticamente, as linhas em que se manifesta a igualdade processual:

1. a) exigência de mesmo tratamento aos que se encontrem na mesma posição jurídica no processo, como, por exemplo, o mesmo tratamento a todos os que ostentem a posição de testemunha, só se admitindo desigualdades por situações pessoais inteiramente justificáveis e que não apresentem prerrogativas inaceitáveis.

2. ) a igualdade de armas no processo para as partes, ou par condicio, na exigência de que se assegure às partes equilíbrio de forças; no processo penal, igualdade entre Ministério Público e acusado.

À perquirição pela legitimidade ou ilegitimidade dos procedimentos investigatórios criminais presididos pelo Ministério Público, interessa verificação da segunda linha em que se manifesta a igualdade processual, ou seja, a paridade de armas para as partes durante a instrução criminal.

A efetivação da igualdade, como se percebe, consiste na árdua e meticulosa tarefa de tratar igualmente os iguais e desigualmente os desiguais. No processo penal, indiscutivelmente, o tratamento diferenciado entre acusação e defesa justifica-se em dois princípios importantes: in dubio pro reo; favor rei (SCARANCE FERNANDES, 2000, p. 50).

Resta evidente a necessidade desse tratamento especial para suprir a inferioridade de oportunidades de que dispõe o acusado, apenas sua força e o auxílio de seu procurador, enquanto a acusação dispõe de todo o aparelhamento estatal para ampará-lo.

No decorrer da instrução criminal, o Ministério Público e a Defesa poderão produzir provas na medida de suas atribuições. Constranger-se-ia o princípio da igualdade entre as partes no processo, especialmente no que tange à paridade de armas, caso ao dominus litis 
fossem acumuladas as funções de colher diretamente as provas na fase de investigação e sem nenhum controle externo, para posteriormente emitir a opinio delicti, fundando-se nas provas por ele mesmo produzidas (MORAIS FILHO, 1997, p. 108).

Desta feita, para que ao Parquet fosse permitida a atividade investigatória na fase preliminar na persecutio criminis, dever-se-ia, pois, sujeitá-lo a um controle externo no momento de opinar pelo arquivamento ou instauração da ação penal, atendendo não apenas ao princípio da igualdade processual, mas também ao contraditório.

\subsection{0 contraditório}

Uma das mais importantes garantias que caracterizam o sistema acusatório, o princípio do contraditório está materializado no Art. 5으, LV da Lei Maior, e constitui um dos pressupostos de desenvolvimento do devido processo legal. Reza o referido dispositivo constitucional: "aos litigantes, em processo judicial ou administrativo, e aos acusados em geral, são assegurados o contraditório e a ampla defesa, com os meios e recursos a ela inerente".

O exercício do contraditório constitui o direito de que dispõem as partes de, em um primeiro momento, estarem cientes da demanda e, nos atos processuais que seguem, terem suas razões apreciadas pelo juízo. Neste sentido, Cintra, Grinover e Dinamarco (2002, p. 55) formulam a prudente explanação:

O juiz, por força de seu dever de imparcialidade, coloca-se entre as partes, mas eqüidistante delas: ouvindo uma, não pode deixar de ouvir a outra; somente assim se dará a ambas a possibilidade de expor suas razões, de apresentar suas provas, de influir sobre o convencimento do juiz.

A efetivação plena no princípio do contraditório, consoante lição de Marques Lima (2002, p. 186-187), compreende duas vertentes: a primeira corresponde à ciência exata da demanda ou acusação; a segunda reporta-se ao exercício do direito intrínseco ao demandado de contrariar a pretensão de seu adversário, combatendo decisões do juiz ou atacando atos dos auxiliares da justiça.

No processo penal, indaga-se quanto a um provável confronto entre a forma pela qual é exercido o contraditório e a igualdade processual. Scarance Fernandes (2000, p. 57) 


\section{A atuação do Ministério Público nas investigações criminais à luz dos princípios constitucionais \\ relacionados}

afirma que a Constituição, ao consagrar o contraditório no Art. 5, LV, garante-o no processo criminal não somente ao acusado, mas também ao Ministério Público.

O tratamento diferenciado, neste caso, data venia, não agride o contraditório, tampouco a igualdade processual. Conforme demonstrado no item antecedente, a igualdade reporta-se ao tratamento igualitário entre os iguais e cuidar com desigualdade os desiguais. Os princípios constitucionais não se excluem, o que ocorre, em determinadas situações, é tão-somente um afastamento de um princípio para que outro, cuja dimensão para o caso concreto é eminente, manifeste-se, sempre com vistas à realização dos objetivos do Estado Democrático de Direito.

A segurança intrínseca ao acusado de se manifestar posteriormente à acusação, excepcionadas determinadas situações, não ofende a igualdade processual, ao contrário, possui o condão de afirmá-la em razão da óbvia posição inferior que a defesa ocupa na colheita de provas em relação ao Ministério Público.

O texto constitucional, em que pese entendimentos contrários, é patente quando menciona a observância do contraditório apenas em processo judicial ou administrativo. 0 inquérito policial ou qualquer outra espécie de investigação preliminar, são atos praticados por uma autoridade administrativa, mas não configuram processo administrativo (SCARANCE FERNANDES, 2000, p. 59).

Logo adiante, a exposição conclusiva de Scarance Fernandes acerca da questão, parece a mais acertada:

\footnotetext{
Há, sem dúvida, necessidade de se admitir a atuação da defesa na investigação, ainda que não se exija o contraditório, ou seja, ainda que não se imponha a necessidade de prévia intimação dos atos a serem realizados. Não se trata de defesa ampla, mas limitada ao resguardo dos interesses mais relevantes do suspeito, como o requerimento de diligências, o pedido de liberdade provisória, de relaxamento de flagrante, a impetração de habeas corpus.
}

A coleta de provas feita pelo Ministério Público na fase de investigações criminal contrapõe-se ao princípio do contraditório não por este se manifestar na fase preliminar na persecutio criminis, mas sim porque, como parte da futura instrução criminal, deve proceder a atos processuais de formação de provas oportunizando ao acusado o direito de contrariar.

Assim, como exemplifica Suannes (2004, p. 243-244), quando membros do Ministério Público tomam depoimentos em seus gabinetes, ainda que - e principalmente - 
não esteja instaurada a ação penal, afasta-se o princípio do contraditório ante a ausência da publicidade do ato que deveria ser processual e não investigatório.

Corroborando o mesmo raciocínio do respeito à paridade de armas entre as partes, para que o Ministério Público efetuasse investigações criminais sem mitigar o princípio do contraditório, deveria estar sujeito a um controle externo, a exemplo do Código Italiano que se preocupou em estabelecer uma diversificação de funções, ainda na fase preliminar, instituindo a figura do giudice per le indagini preliminari (MORAIS FILHO.1997, p. 107), a quem compete a manifestação concernente a determinadas questões probatórias, o exame do pedido de arquivamento e decisão quanto à instauração de ação penal, após uma audiência preliminar, de caráter contraditório, momento em que é possível até mesmo a coleta de novas provas.

O risco reside na consciência do representante do Parquet em resguardar sua imparcialidade no momento de propor a ação penal diante de provas coletadas por ele mesmo.

Como ser humano, não está isento da vaidade de considerar as provas que recolheu cabais à instauração da ação penal, mesmo que não sejam. Ou, em outro sentido, como assevera Morais Filho (1997, p. 108), direcionando o representante ministerial a coleta de provas favoravelmente ao indiciado, intencionalmente ou não, necessariamente opinará pelo arquivamento que, por sua vez, tornar-se-ia obrigatório quando ratificado pelo Procurador-Geral, mesmo com a discordância do juiz. Constatando-se, destarte, também grave comprometimento ao próprio princípio da obrigatoriedade da ação penal.

\section{Conclusão}

A sociedade brasileira tem sido sujeitada diariamente a conviver com a violência das ruas e a corrupção das autoridades. A polícia judiciária, tal como as demais instituições de atribuição específica na estruturação do Estado Democrático de Direito, não está isenta da doce tentação de corromper-se. Em face disto, a sociedade vê-se, se não desamparada pelo Estado, ao menos preterida no rol de prioridades estatais, especialmente no que concerne à tutela da segurança individual e patrimonial, preservação e devida aplicação do dinheiro público. 


\section{A atuação do Ministério Público nas investigações criminais à luz dos princípios constitucionais relacionados}

Insta verificar, primeiramente, que a generalização não é o método mais adequado à busca de soluções em qualquer área problemática. Vale dizer, o problema não consiste apenas na instituição policial e nem todos os seus integrantes são desonestos. O ser humano está sujeito a erros e fraquezas próprios de sua essência ou exteriores a ela; o fato de ser membro do Ministério Público ou da Magistratura não impermeabiliza o indivíduo da possibilidade de erro ou incidência de fraquezas.

O ordenamento constitucional em momento algum legitimou o Ministério Público a presidir investigações criminais preliminares ou realizar diretamente diligências investigatórias. O Art.129, por meio de seus incisos VII e VIII, corroborou, respectivamente, a função do Parquet no exercício do controle externo da polícia judiciária e o poder requisitório para realização de diligências investigatórias, na fase de preliminar da persecutio criminis, e instauração de inquérito policial, na busca por elementos de conviç̧ão suficientes a formar a opinio delicti.

O sistema de persecução penal adotado pelo Brasil e recepcionado pela Constituição Federal de 1988, foi estruturado de modo a bem diferenciar o órgão competente a colher provas preliminarmente à ação penal daquele responsável pela avaliação da consistência probatória das investigações, a quem compete propor a ação penal, exercer a função acusatória sem, contudo, afastar-se de sua atividade de arauto da efetivação de direitos e garantias fundamentais, interesses difusos e coletivos.

No momento de propositura da ação penal, deve o representante do Ministério Público revestir-se de coerente imparcialidade e compromisso exclusivo com a justiça, uma vez que não lhe compete atuar como "procurador da vítima". A coleta de provas da fase preliminar realizada diretamente pelo dominus litis pode interferir nessa imparcialidade, de modo que, no momento de avaliar provas para propositura da ação penal, tendencioso estará a considerá-las suficientemente consistentes para transformar o indiciado em réu.

A legitimação da função investigatória do Parquet no âmbito criminal deve, necessariamente, passar pelo processo legislativo adequado, dada a importância da matéria tratada. Legitimada a função, esta não prescinde de regulamentação específica, em que seria previsto, além da especialidade das hipóteses de investigação criminal presidida pelo Ministério Público, um mecanismo de controle de seus membros visto que estes não se eximem do risco de erros e fraquezas. 
Na medida em que o Ministério Público forma provas sem que seja dada a ciência e oportunidade de manifestação à Defesa, o princípio do contraditório é preterido. A igualdade processual, especialmente no que toca à paridade de armas, é mitigada no mesmo instante pois, além da cumulação indevida das funções de colher provas a seu talante e emitir a opinio delicti com fulcro nestas, desencadeando a ação penal, o mais grave seria conceber que, posteriormente, certamente uma corrente jurisprudencial formar-se-ia reconhecendo como suficiente, para efeito condenatório, a prova colhida pelo Ministério Público na fase preliminar, em homenagem à credibilidade da fonte de que se emanou (MORAIS FILHO, 1997, p. 108).

Incoerente é, na defesa da legitimação constitucional da função investigatória criminal do Ministério Público, a aplicação da teoria dos poderes implícitos pois a atividade da polícia judiciária em realizar diligências não é menos que a requisição para tanto pelo Ministério Público (BARROSO, 2004), portanto, a competência para uma atividade não está implícita na outra.

Em suma, o Ministério Público não é legitimado a proceder diretamente a diligências investigatórias ou presidir a fase de investigação, tudo no âmbito criminal. Isto não apenas porque a Constituição ou as Leis Complementares que dispõem e regulamentam as funções institucionais do Ministério Público da União e dos Estados não autorizam, mas principalmente em atenção à preservação de princípios constitucionais como o contraditório, a paridade de armas e, ipso facto, o devido processo legal.

A boa-fé dos membros do Parquet em proceder investigações criminais deve ser presumida, bem como a dos agentes policiais. A distinção evidente reside da existência de mecanismos de controle destes no desempenho de suas atividades. Na hipótese de se autorizar a função investigatória criminal do dominis litis, imprescindível é a especificação criteriosa dos momentos desta atuação e, fundamentalmente, a instituição de um órgão de controle.

\section{Referências}

ARAúJO CINTRA, Antonio C. D.; GRINOVER, Ada P.; DINAMARCO, Candido R. Teoria Geral do Processo. 18. ed. São Paulo: Malheiros, 2002. 
BARROSO, Luís Roberto. Investigação pelo Ministério Público. Argumentos contrários e a favor. A síntese possível e necessária. Rio de Janeiro, 22 jan. 2004. Disponível em: <http://www.mp.rs.gov.br/hmpage/homepage2nsf/pages/spi_investigadireta2> . Acesso em: 18 mai. 2005.

CLÁUDIO, Paulo; TOVO, João Batista. Primeiras linhas sobre o Processo Penal em face da nova Constituição. Porto Alegre: Sergio Antonio Frabis, 1989.

FERNANDES, Antonio Scarance. Processo Penal Constitucional. 2. ed. São Paulo: Revista dos Tribunais, 2000.

FRAGOSO, José Carlos. São ilegais os "procedimentos investigatórios" realizados pelo Ministério Público Federal. Revista Brasileira de Ciências Criminais, São Paulo, n. 37, p. 241251, jan./mar. 2002.

GOMES, Luiz Flávio; BIANCHINI, Alice. O Direito Penal na Era da Globalização. São Paulo: Revista dos Tribunais, 2002. p. 58.

JARDIM, Afrânio Silva. Ação Penal Pública. Princípio da Obrigatoriedade. 3. ed. Rio de Janeiro: Forense, 1998. p. 17.

MARQUES DE LIMA, Francisco G. Fundamentos constitucionais do processo. São Paulo: Malheiros, 2002.

MORAIS FILHO, Antonio E. O Ministério Público e o Inquérito Policial. Revista Brasileira de Ciências Criminais, São Paulo, n. 19, p. 103-110, jul./set. 1997.

PRADO, Luiz Regis. Bem jurídico-penal e Constituição. 3. ed. São Paulo: Revista dos Tribunais, 2003.

RANGEL, Paulo. Investigação Criminal Direta pelo Ministério Público.Visão Crítica. Rio de Janeiro: Lumen Juris, 2003.

SANTOS CABETTE, Eduardo L. O papel do Inquérito Policial no Sistema Acusatório - o modelo brasileiro. Revista Brasileira de Ciências Criminais, São Paulo, n.37, p. 185-201, jul./set. 2001.

SILVA, José Afonso da. Curso de Direito Constitucional. 19. ed. São Paulo: Malheiros, 2000.

STRECK, Lênio Luiz; FELDENS, Luciano. Crime e Constituição. A legitimidade da função investigatória do Ministério Público. Rio de Janeiro: Forense, 2003. 
STRECK, Lênio Luiz. Jurisdição Constitucional e Hermenêutica. 2. ed. Rio de Janeiro: Forense, 2004.

SUANNES, Adauto S. Os fundamentos éticos do devido processo penal. São Paulo: Revista dos Tribunais, 2004.

TOURINHO FILHO, Fernando da Costa. Código de Processo Penal comentado. v.1. 3. ed. São Paulo: Saraiva, 1998.

TOURINHO FILHO, Fernando da Costa. Processo Penal. 19. ed. São Paulo: Saraiva, 1997. v. 1.

VALLE, Anco Márcio. Segurança Pública, planejamento, política e controle da atividade policial.In: 13을 Congresso Nacional do Ministério Público, 1999. Livro de Teses. v.1. tomo 1. Curitiba: Núcleo Ltda, 1984. 